\title{
Radiation therapy for oral melanoma in dogs: A retrospective study
}

\section{Simone Carvalho dos Santos Cunha ${ }^{*}$ Katia Barão Corgozinho ${ }^{2}$ Franciele Basso Fernandes Silva ${ }^{3}$ Kassia Valéria Gomes Coelho da Silva ${ }^{4}$ Ana Maria Reis Ferreira ${ }^{4}$}

'Programa de Pós-doutorado, Faculdade de Medicina Veterinária, Universidade Federal Fluminense (UFF), Rua Vital Brazil Filho, 64, 24230.340, Niterói, RJ, Brasil. E-mail: simonescs@gmail.com. .Corresponding author.

${ }^{2}$ Programa de Pós-doutorado, Instituto de Medicina Veterinária, Universidade Federal Rural do Rio de Janeiro (UFRRJ), Rio de Janeiro, RJ, Brasil. ${ }^{3}$ Programa de Pós-graduação em Patologia, Faculdade de Medicina, Universidade Federal Fluminense (UFF), Niterói, RJ, Brasil. Curso de Medicina, Universidade Federal do Piauí (UFPI), Teresina, PI, Brasil.

${ }^{4}$ Programa de Pós-graduação em Medicina Veterinária (Clínica e Reprodução Animal), Universidade Federal Fluminense (UFF), Niterói, RJ, Brasil.

ABSTRACT: Our retrospective study evaluated the survival of 24 dogs with unresectable malignant melanoma treated with radiation therapy. Fifteen dogs were treated with radiation therapy (RT) and chemotherapy (CT), five with surgery followed by $R T$ and CT, three with palliative $R T$, and one with electrochemotherapy associated with RT. All dogs were treated with an orthovoltage Stabilipan I. The protocol used was three or four weekly fractions of $8 \mathrm{~Gy}$. Carboplatin was administered every 21 days, a total of four times. Five percent of dogs were classified as having stage I melanoma, $17 \%$ as stage II, $50 \%$ as stage III, and $17 \%$ as stage IV. Sixty-four percent had a partial response to treatment, $29 \%$ achieved complete remission, and 7\% remained in a stable disease state. The mean survival time was 390 days for stage I, 286 days for stage II, 159 days for stage III, and 90 days for stage IV. We concluded that radiation therapy can be considered a viable alternative for the palliative treatment of canine oral melanoma.

Key words: neoplasia, radiation, oral cavity.

A utilização da radioterapia no melanoma oral de cães: Estudo retrospectivo

RESUMO: O estudo retrospectivo analisou a sobrevida de 24 cães com melanomas irressecáveis tratados com radioterapia (RT). Quinze animais foram tratados com RT e quimioterapia (QT), 5 animais com cirurgia citoredutiva seguida por RT e QT, 3 animais com RT paliativa apenas e 1 animal com RT associada a 1 sessão de eletroquimioterapia. Os animais foram tratados com um equipamento de ortovoltagem Stabilipan I, $e$ o protocolo foi de três a quatro frações semanais de 8 Gy. A quimioterapia consistiu de carboplatina administrada a cada 21 dias em um total de 4 aplicações. Apenas um animal (4\%) foi classificado em estadio I, enquanto quatro (17\%) estavam no estadio II, doze (50\%) estavam no estadio III e quatro (29\%) estavam no estadio IV. De maneira geral, 64\% dos cães apresentaram resposta parcial, 29\% remissão completa e 7\% doença estável. O tempo médio de sobrevida foi de 390 dias no estádio I, 286 dias no estádio II, 159 dias no estádio III e 90 dias no estádio IV. A radioterapia deve ser considerada pelo clínico veterinário como alternativa para o tratamento de melanoma oral canino.

Palavras-chave: neoplasias, radiação, cavidade oral.

\section{INTRODUCTION}

Oral melanoma is a highly aggressive and metastatic neoplasm in dogs (HARVEY et al., 1981; HAHN et al., 1994; SPANGLER \& KASS, 2006). It is classified in four stages (I-IV), using a graduation used for humans adapted from the World Health Organization (Table 1) (BERGMAN, 2007).

Surgery and radiation therapy are treatment options for the local control of oral melanoma. Surgery must be aggressive, and partial mandibulectomy or maxillectomy is often necessary. However, due to the high local aggressiveness of oral melanoma, and as most cases are diagnosed in the advanced stages (with tumors greater than $4 \mathrm{~cm}$ and/or regional lymph node metastasis), aggressive surgery often becomes unfeasible or is declined by the owner (BERGMAN, 2007). The survival time (ST) of dogs treated with aggressive surgery is approximately 17 months for stage I, five months for stage II, and three months for stage III (MACEWEN et al, 1986). Chemotherapy is indicated due to its high metastatic potential, but the real benefit of chemotherapy for canine melanoma is not yet well-established (Blackwell \& Doson, 1996; RASSNICK et al., 2001; 2014).

Radiation therapy plays an important role in the treatment of canine oral melanoma when surgery is not possible, or when the surgical resection is incomplete. It may also be used as a palliative treatment for dogs with regional lymph node or distant metastases, with partial remission of the mass, control of pain, and increased quality of life 
Table 1 - Clinical staging of melanoma in dogs according to the World Health Organization (OWEN, 1980).

\begin{tabular}{lc}
\hline Estage & Definition \\
\hline I & $<2 \mathrm{~cm}$ in diameter, with no evidence of lymph node metastases $)$ \\
II & 2 to $4 \mathrm{~cm}$ in diameter, with no evidence of lymph node metastasis \\
III & $>4 \mathrm{~cm}$ in diameter and/or lymph node metastasis \\
IV & Any size with evidence of distant metastases \\
\hline
\end{tabular}

(BERGMAN, 2007; LARUE \& GILLETTE, 2007). Some radiation therapy protocols consist of weekly fractions of 6-9 Gy, with a total dose of 24-36 Gy, and average a 53\%-69\% complete remission rate and $25 \%-30 \%$ partial remission rate. However, local recurrence and/or distant metastases are common after treatment (BATEMAN et al, 1994; BLACKWOOD \& DOBSON, 1996; FREEMAN et al., 2003, PROULX et al., 2003; LARUE \& GILLETTE, 2007).

The type of radiation equipment used influences the dose distribution in the tumor. Orthovoltage machines produce $\mathrm{X}$-rays with a power of $150-500 \mathrm{kVp}$, while megavoltage machines (cobalt-60 and linear accelerators) emit photons of energy greater than $1,000,000$ volts. The most important difference between orthovoltage and megavoltage machines is the photon energy produced. High-energy photons deposit a greater amount of energy (dose) below the surface of the skin, while the orthovoltage machine's low-energy photons deposit the dose of radiation on the surface of the skin. Thus, megavoltage is indicated for deeper tumors (LARUE \& GILLETTE, 2007).

The purpose of this study was to evaluate the survival of dogs with unresectable oral melanomas treated with adjuvant orthovoltage radiotherapy, with or without regional or distant metastases, or with partially excised metastases.

\section{MATERIALS AND METHODS}

Our retrospective study was performed with dogs with histological diagnoses of oral melanoma that attended a private veterinary clinic between August 2011 and January 2014.

For the histopathological diagnosis, collected fragments were immediately immersed in $10 \%$ formalin buffered solution for a period of 24 48 hours. During histopathological processing, the fragments were cleaved, dehydrated, diaphanized, and later processed and stored in paraffin. Histological sections were stained with hematoxylin-eosin.

The overall conditions of all dogs were carefully assessed. They were then submitted to complete clinical staging, which included primary tumor measurement, regional lymph node evaluation, thoracic radiographs, abdominal ultrasonography, and hematological and biochemical examinations. Lesions were measured using a pachymeter, and clinical staging was performed according to the World Health Organization classification (BERGMAN, 2007): category " $T$ " corresponded to the size of the primary neoplasia, "N" to the presence of the involvement of the lymph nodes, and " $M$ " to the presence of distant metastases (Table 1). When mandibular lymph node involvement was suspected, fine needle aspiration was performed. Tumors of $<2 \mathrm{~cm}$ in diameter with no evidence of lymph node metastases were classified as stage I, stage II tumors were $2-4 \mathrm{~cm}$ in diameter with no evidence of lymph node metastasis, stage III tumors were $>4 \mathrm{~cm}$ in diameter and/or of any size when metastasis was present in the lymph nodes, and stage IV tumors were of any size with evidence of distant metastases (OWEN, 1980).

Radiation therapy was used for three purposes: as an adjuvant therapy when the surgery failed to achieve adequate margins, as a palliative treatment for pain control and partial remission in advanced and unresectable cases, or for local tumor control when surgery with adequate margins (mandibulectomy or maxilectomy) was declined by the owner. When regional lymph node metastases were present, they were included in the radiation field.

The dogs were treated at a private veterinary clinic with Stabilipan I orthovoltage equipment. Treatment planning was performed with a medical physicist, and based on a percentage depth table (\%DD) and dose rate, which were previously established from dosimetric tests performed on the equipment. A hypofractionated radiation protocol (3-4 fractions of 8 Gy performed once a week; a total of 24-32 Gy) was used. In three fractions protocols, the treatments were performed on days zero, seven, and 21, while in four fractions protocols the treatment was performed over four consecutive weeks, every seven days. Energy of $120-140 \mathrm{Kv}, 15-\mathrm{mA}$ and $2 \mathrm{~mm}$ of aluminum filter, or $0.5 \mathrm{~mm}$ of copper were used, depending on the extent of the lesion. Focus-skin distance was $30 \mathrm{~cm}$, and the dose rate was $140 \mathrm{cGy} / \mathrm{min}$. For the determination of 
the treatment field, a $3 \mathrm{~cm}$ margin was given around the tumor or surgical scar. One mm thick lead sheets were used to protect the healthy areas around the tumor.

Dogs were anesthetized with propofol $^{\mathrm{a}}$ $(4 \mathrm{mg} / \mathrm{kg}$ dose effect intravenously), and inhalation anesthetic maintenance was performed with isoflurano ${ }^{\mathrm{b}}$ (via endotracheal tube) to ensure the correct positioning in all radiation fractions. During radiation delivery (the administration of the ionizing radiation by the equipment), all persons remained outside the room, and only the patient received radiation. Patient monitoring was possible via a system of cameras and video terminals. Their breathing and position were observed in a monitor located outside the radiation therapy room, and if necessary, treatment could be discontinued. Patients were followed throughout the treatment, and the evolution of their lesions was monitored using digital photographic cameras. A complete response (CR) was defined as a total remission of the tumor, a partial response (PR) as a tumor remission of $30 \%$ or more, and stable disease (SD) as a tumor remission of less than $30 \%$, or tumor progression. Biweekly (within the first three months) and monthly (over the subsequent months) revisions were performed after treatment, for complete clinical examination, supportive treatment, and laboratory and/or imaging exams.

Systemic chemotherapy was indicated in all cases, with two objectives: to act as a radio-potentiating agent and to prevent or delay metastases. However, in some cases, chemotherapy was declined by the owners. Carboplatin ${ }^{\mathrm{c}}\left(250-300 \mathrm{mg} / \mathrm{m}^{2}\right)$ was administered intravenously every 21-30 days, for a total of four doses. The first dose was administered approximately 5-7 days before the radiation therapy started. Blood exams were performed before each chemotherapy dose, to assess chemotherapyinduced myelosuppression. Electrochemotherapy (a modality that combines intralesional bleomycin associated with electroporation) was indicated as an adjuvant therapy in one case of absence of bone invasion by the tumor. Bleomycin ${ }^{\mathrm{d}}$ was administered directly into the lesion at a dose of $1 \mathrm{IU} / \mathrm{cm}^{3}$, and biphasic pulses (eight biphasic pulses lasting $50+50 \mu \mathrm{s}$ each, with a frequency of $1 \mathrm{~Hz}$ ) were applied immediately after the bleomycin injection, to the tumor and a $1 \mathrm{~cm}$ margin around it.

Radiation side effects were evaluated by clinical examination of the patient, before each radiotherapy fraction, and 15-30 days after treatment. Supportive medications (including analgesics, antiinflammatories, and antibiotics) were prescribed as needed. After this period, the patients were re-evaluated every 30-60 days. Chemotherapy side effects were evaluated via owner anamnesis and hematological examinations performed before each dose.
Statistical analysis took the form of database and exploratory analyses, using the chi-square and Spearman's correlation tests for comparisons between variables. For the analysis of global survival and disease free interval (DFI), the Kaplan-Meier test (with the Mantel log-rank test of statistical significance) was used. Values were considered significant when the p-value was $<0.05$. The analysis was performed using SPSS software version 20.0 (IBM SPSS).

\section{RESULTS}

Twenty-four dogs diagnosed with oral melanoma were treated. Ages ranged from 8-18 years, with a mean and standard deviation of $13 \pm 2.6$ years (Table 2). According to tumor staging, only one patient ( $4 \%$ of the sample) was classified as stage I, while four $(17 \%)$ were stage II, twelve $(50 \%)$ were stage III, and four $(29 \%)$ were stage IV. For the purposes of statistical evaluation, the stage I group was withdrawn because it contained only one patient. Thus, a statistically significant difference regarding disease stage and treatment response (partial remission, total remission, or stable disease) $(P=0.006)$ was observed. Dogs with advanced oral melanoma stages (87; 5\% stage III and 50\% stage IV) had more frequent partial remission to treatment, while all dogs with stage II melanomas achieved complete remission, as can be observed in figure 1 .

Fourteen dogs (58.3\% of the sample) already had regional lymph node metastases at the time of initiation of treatment, while seven (29.2\%) also had distant metastases (four cases in the lungs, two in the central nervous system, and one in the abdominal lymph nodes) (Figure 2). In these cases, the owners who declined euthanasia opted for radiotherapy only to improve their pet's pain and comfort levels. Twelve dogs had already undergone previous treatments, which included surgery (six) and chemotherapy (six).

The treatment protocol option varied with the general condition of the dog, presence of concomitant diseases, and the owner's treatment decision. Of the 24 dogs, 15 were treated with radiation therapy and chemotherapy, five with cytoreductive surgery followed by radiation therapy and chemotherapy, three with palliative radiation therapy alone, and one with radiation therapy associated with one session of electrochemotherapy (performed 60 days after the end of the radiation therapy). In dogs whose carboplatin was administered 5-7 days prior to the radiation therapy, no macroscopic tumor reduction was observed on oral examination at the start of the radiation therapy. The radiation therapy protocol was three sessions of 800cGy in 16 dogs and four sessions of $800 \mathrm{cGy}$ in eight dogs. 
Table 2 - Age, bredd, tumor stage, presence of metastases at the time of diagnosis, previous treatments, intention of radiation therapy, number of fractions applied, response, disease free interval, survival time and follow-up of 24 dogs with oral melanoma treated through radiation therapy.

\begin{tabular}{|c|c|c|c|c|c|c|c|c|c|c|}
\hline A & Age & Breed & Stage & Metastasis & Treatment & $\mathrm{N}$ & Response & DFI & ST & Follow-up \\
\hline 1 & 16 & Poodle & IV & $\mathrm{LN} / \mathrm{CNS}$ & RT & 2 & NT & - & 60 & Death/CNS metastasis \\
\hline 2 & 13 & Cocker & III & LN & $\mathrm{CT} / \mathrm{RT}$ & 4 & PR & - & 150 & Death/Lung metastasis \\
\hline 3 & 15 & Dachshund & IV & LN/Lungs & RT & 4 & SD & - & 60 & Death/Lung metastasis \\
\hline 4 & 15 & Fox paulistinha & II & - & $\mathrm{CT} / \mathrm{RT}$ & 3 & PR & -210 & 240 & Death/Lung metastasis \\
\hline 5 & 13 & $\begin{array}{l}\text { Golden } \\
\text { retriever }\end{array}$ & III & - & $\mathrm{S} / \mathrm{CT} / \mathrm{RT}$ & 3 & PR & - & 380 & Death/Lung metastasis \\
\hline 6 & 16 & SRD & III & LN & $\mathrm{CT} / \mathrm{RT}$ & 3 & $\mathrm{CR}$ & 365 & 390 & Death/pulmonary edema \\
\hline 7 & 15 & Lhasa apso & II & - & $\mathrm{CT} / \mathrm{RT}$ & 3 & $\mathrm{CR}$ & 150 & 210 & Death/Lung metastasis \\
\hline 8 & 16 & Poodle & III & LN & $\mathrm{CT} / \mathrm{RT}$ & 3 & PR & - & 90 & Death/Lung metastasis \\
\hline 9 & 13 & Cocker & III & LN & $\mathrm{CT} / \mathrm{RT}$ & 4 & PR & - & 180 & Lost contact \\
\hline 10 & 13 & Pug & IV & LN/Lungs & $\mathrm{CT} / \mathrm{RT}$ & 1 & IT & - & 90 & Death/Lung metastasis \\
\hline 11 & 13 & Daschund & II & - & $\mathrm{S} / \mathrm{CT} / \mathrm{RT}$ & 4 & CR & 210 & $380^{*}$ & In follow-up \\
\hline 12 & 12 & Yorkshire & III & $\mathrm{LN}$ & $\mathrm{CT} / \mathrm{RT}$ & 1 & IT & - & 6 & Death/sepsis \\
\hline 13 & 13 & Cocker & I & - & $\mathrm{CT} / \mathrm{RT}$ & 3 & PR & 390 & 390 & Death/CNS metastasis \\
\hline 14 & 14 & Daschund & III & $\mathrm{LN}$ & $\mathrm{CT} / \mathrm{RT}$ & 3 & PR & - & 180 & Death/Lung metastasis \\
\hline 15 & 11 & Daschund & IV & $\mathrm{LN} / \mathrm{CNS}$ & $\mathrm{CT} / \mathrm{RT}$ & 2 & IT & - & 30 & Death/CNS metastasis \\
\hline 16 & 18 & Poodle & IV & LN/Lungs & RT & 2 & IT & - & 21 & Death/Multiple metastasis \\
\hline 17 & 12 & Srd & II & - & RT/ECT & 3 & $\mathrm{CR}$ & 120 & $314^{*}$ & In follow-up \\
\hline 18 & 9 & West highland & III & - & $\mathrm{CT} / \mathrm{RT}$ & 4 & PR & - & 30 & Death/oral tumor progression \\
\hline 19 & 8 & Rottweiller & III & LN & $\mathrm{CT} / \mathrm{RT}$ & 4 & PR & - & $150^{*}$ & In follow-up \\
\hline 20 & 17 & Srd & IV & LN/Lungs & $\mathrm{CT} / \mathrm{RT}$ & 2 & IT & - & 90 & Death/Lung and heart metastasis \\
\hline 21 & 9 & Schnauzer & III & - & $\mathrm{S} / \mathrm{CT} / \mathrm{RT}$ & 4 & - & - & $40^{*}$ & In follow-up \\
\hline 22 & 12 & Lhasa apso & III & - & $\mathrm{S} / \mathrm{CT} / \mathrm{RT}$ & 3 & - & 408 & $408^{*}$ & In follow-up \\
\hline 23 & 10 & Labrador & IV & LN/abdome & $\mathrm{CT} / \mathrm{RT}$ & 3 & PR & - & 130 & Death/Multiple metastasis \\
\hline 24 & 11 & Srd & III & - & $\mathrm{S} / \mathrm{CT} / \mathrm{RT}$ & 3 & - & - & $69^{*}$ & In follow-up \\
\hline
\end{tabular}

A - Animal; LN - Lymph nodes; CNS - Central Nervous system; CT - Chemotherapy; RT - Radiation Therapy; ECT: Electrochemotherapy; N - Number of radiation fractions IT - Incomplete treatment; PR - Partial remission; CR - Complete remission; SD - Stable disease; DFI - Disease free interval; ST - Survival time. ${ }^{*}$ Live animals and in follow-up.

The aim of radiation therapy was palliative in 21 cases (with unresectable or metastatic tumors) and adjuvant after incomplete excision in three cases. However, due to the presence of metastases in many dogs in the sample, only 17 of 24 dogs were able to complete the planned protocol.

Of the 14 dogs submitted to palliative radiation therapy that concluded treatment, nine $(64 \%$ of the sample) presented with partial tumor remission, four $(29 \%)$ with complete remission, and one $(7 \%)$ with stable disease (Figure 2). Among the dogs that achieved complete remission, the tumor began to reduce during the third and fourth weeks of treatment. Among the three dogs submitted to adjuvant radiation therapy after incomplete surgical excision, one obtained local tumor control for nine months after treatment, before local recurrence and metastasis. The other two dogs are still in complete remission and are being followed.
Radiation acute side effects involved only mild epilation and cutaneous erythema in the irradiated field, and use of an e-collar or anti-inflammatory topical treatment was not needed (Figure 2). Epilation persisted for 30-45 days after the end of treatment, and the coat grew depigmented and shorter.

Mean DFI among the dogs studied that achieved complete tumor remission was 212.5 days, and the mean ST was 300 days. By the study deadline, six dogs were still under follow-up, one was lost to follow-up, and fourteen died of distant metastases to sites including the lungs, central nervous system, abdominal organs, and heart. One dog died due to oral tumor progression, one due to cardiogenic pulmonary edema, and one due to sepsis.

The mean ST of dogs submitted to radiation therapy alone was 47 days, while dogs that underwent radiation therapy and chemotherapy had an average ST of 157 days. When subdivided according to 


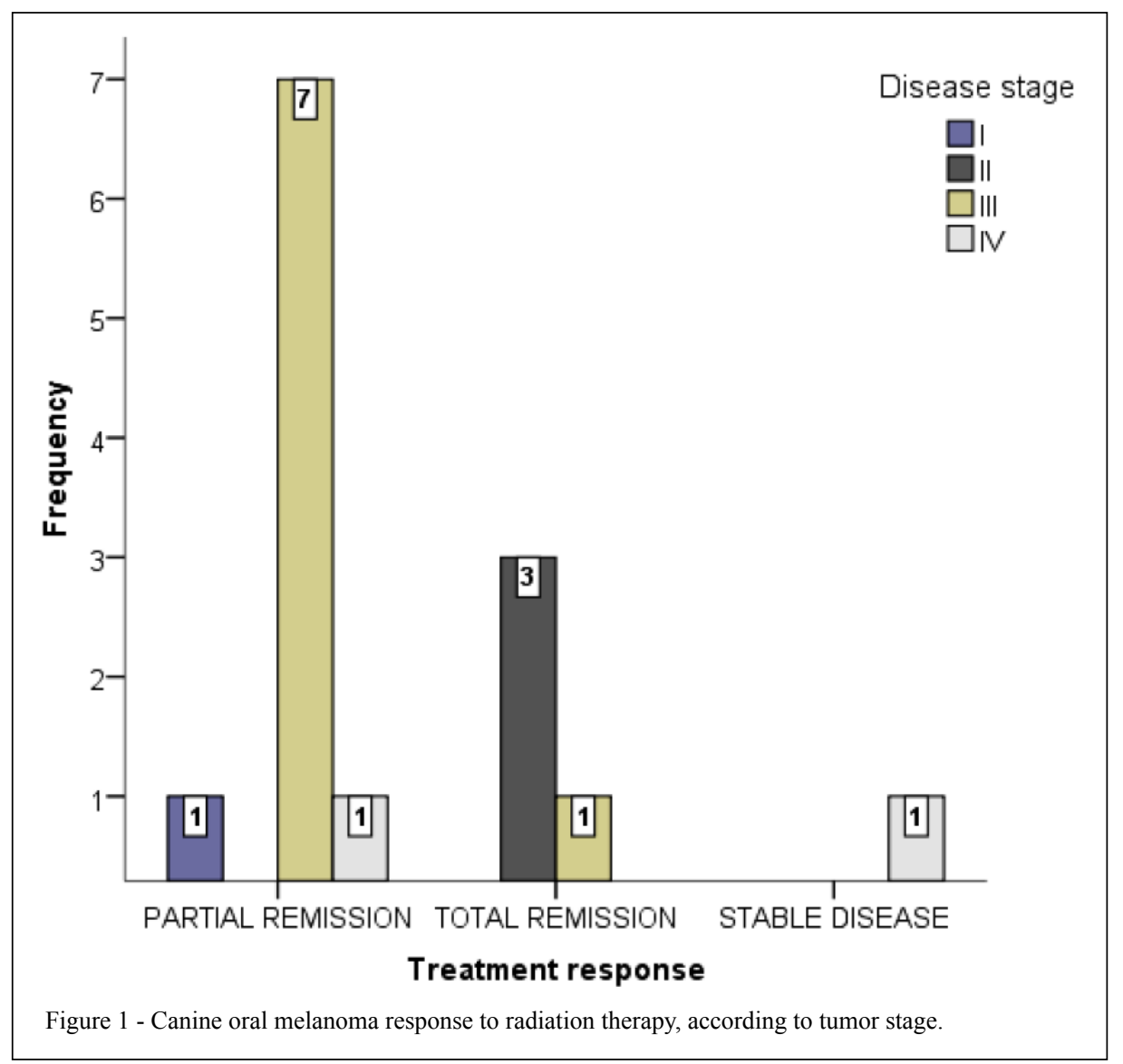

tumor stage, a statistically significant difference was observed in relation to ST $(\mathrm{P}=0.018)$, and dogs at stage II had a significantly longer ST when compared to dogs at stage IV. The mean and median cases in the stage group were, respectively, stage I: 390 days for both, stage II: 286 of 277 days, stage III: 159 of 120 days, and stage IV: 90 days for both (Figure 3). ST was not statistically significant when compared with treatment response $(\mathrm{P}=0.12)$ (Figure 4). However, when we viewed the survival curve according to the treatment applied (Figure 5), we observed that there was a statistically significant difference $(\mathrm{P}=0.04)$ : that dogs receiving surgery/chemotherapy/radiation therapy showed a greater mean ST (mean: 253 days, median: 380 days), followed by dogs treated with chemotherapy/radiation therapy (mean: 155 days, median: 150 days), and finally, by those treated with radiation therapy alone (mean: 47 days, median: 60 days). Likewise, a statistically significant difference was observed between treatment applied and death rate $(\mathrm{P}=0.007)$ : dogs submitted to radiation therapy or chemotherapy/radiation therapy had a higher number of deaths, $100 \%$ and $86.7 \%$, respectively. In saying this, only $20 \%$ of the dogs submitted to the surgery/ chemotherapy/radiation therapy treatment died.

DFI analysis was possible in seven animals, with a mean of 265 days. When we grouped cases according to stage, there was no statistically significant difference $(\mathrm{P}=0.19)$ for DFI (Figure 6). The seven animals with an established ST were stage I (one case), II (four cases), and III (two cases). The mean/median cases at stages II and III were 172/180 and 389/389, respectively. When comparing the DFI with treatment response or with type of treatment, no statistically significant differences were observed $(\mathrm{P}>0.05)$.

\section{DISCUSSION}

Melanoma is the most common oral tumor of dogs, affecting mainly older animals (HARVEY et al., 1981; HAHN et al., 1994). Cinical signs of melanoma include a visible mass in the oral cavity, oral bleeding, halitosis, dysphagia, and oral pain (HARVEY et al, 1981; HAHN et al, 1994), all of which were observed in the dogs studied. Metastases are early and frequent, and occur mainly in the regional lymph nodes and lungs, and 


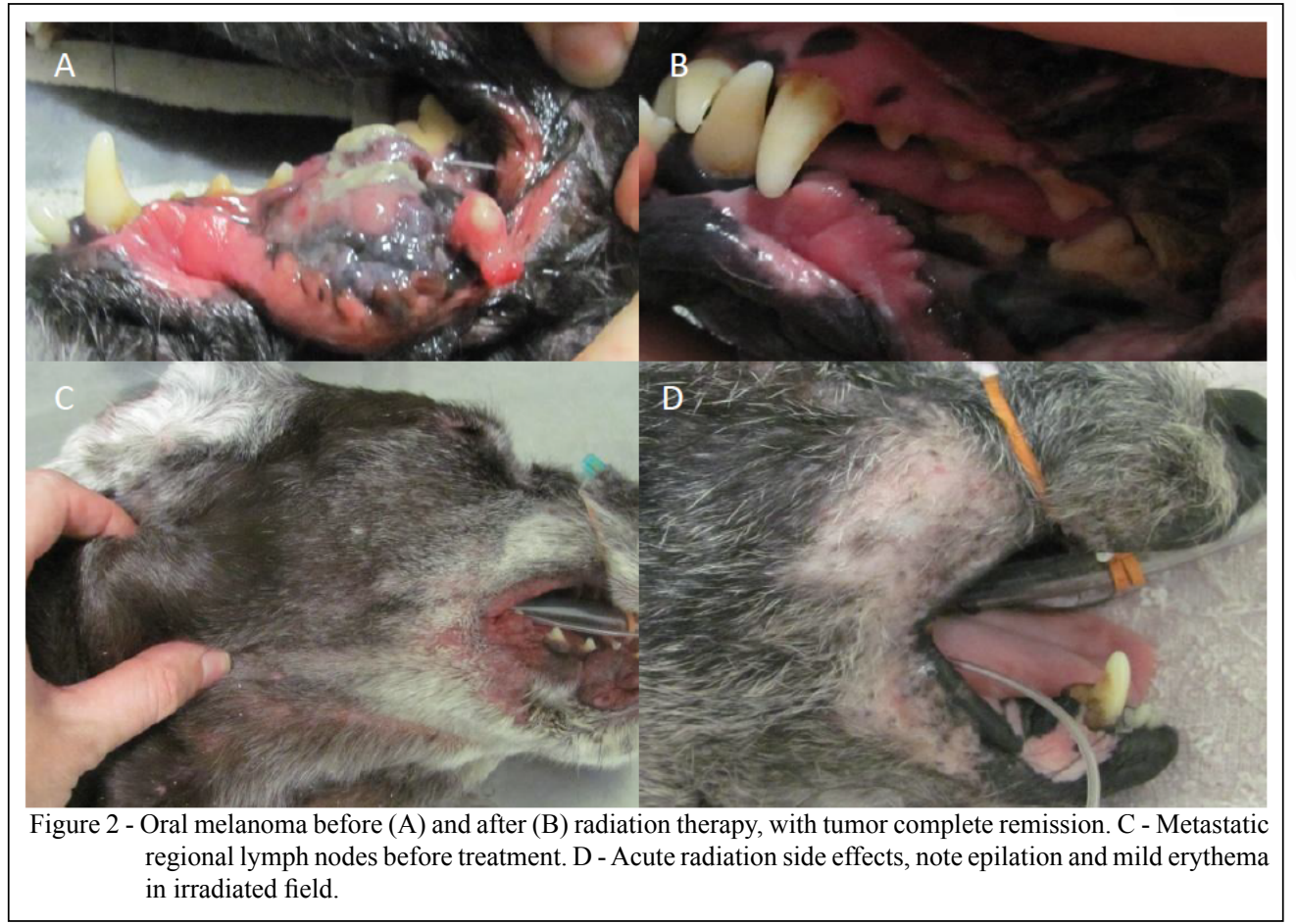

occasionally in the kidneys, myocardium, brain, and other sites (OGILVIE \& MOORE, 1995). In this study, fourteen dogs had regional lymph node metastasis and six had distant metastases (to the lungs, central nervous system, or abdominal lymph nodes) at the time of diagnosis.

Radiation therapy was performed in most cases with palliative intention, to reduce tumor size and minimize animal discomfort. Nine dogs (64\% of the sample) presented with tumor partial remission, four $(29 \%)$ with complete remission, and one $(7 \%)$ with stable disease. Radiation therapy was able to cause partial or total mass reduction, leading to better patient quality of life, even in dogs with regional and/ or distant metastases. Previous studies have shown that radiation therapy is an effective treatment for dogs with oral melanoma, with high rates of complete or partial remission (BATEMAN et al., 1994; BLACKWOOD \& DOBSON, 1996; FREEMAN et al., 2003; PROULX et al., 2003; et al., 2007; LARUE \& GILLETTE, 2007). One study used megavoltage radiation therapy with a protocol similar to that used in our study (three fractions of 8Gy performed on days zero, seven, and 21) in 17 dogs with oral melanoma, and obtained a $53 \%$ complete remission rate and a $30 \%$ partial remission rate (BATEMAN et al, 1994). In the present study, the number of partial remissions $(64 \%$ of the sample) was higher than in the cited literature (30\%), which may be explained by the difference in the type of radiotherapy (orthovoltage and megavoltage) and lower dose distribution in very large tumors.

The mean DFI among dogs in the sample that achieved complete remission was 212.5 days, while the mean ST was 300 days. When subdivided according to tumor stage, the mean and median were both 390 days for stage I, 286 and 277 days for stage II, 159 and 120 days for stage III, and both 90 days for stage IV, respectively. In previous literature, the ST of dogs treated with aggressive surgery is approximately 510 days for stage I, 360 days for stage II, and 90 days for stage III (MACEWEN et al, 1986). When analyzing these results, it is possible to observe that radiation therapy leads to a somewhat lower ST for stages I and II when compared to aggressive surgery, but to a higher ST in the advanced stages (III and IV).

The ST of animals treated with aggressive surgery is approximately 510 days for stage I, 360 days for stage II, and 90 days for stage III (MACEWEN et al, 1986). Surgical treatment of oral melanoma may interfere with food seizure and tongue positioning, and thus decrease the dog's quality of life. Therefore, surgery is declined by some owners, mainly on behalf of geriatric and/or debilitated dogs. In the present study, radiation therapy was able to improve the ST of dogs that could not undergo aggressive surgery. Previous studies have also described partial or complete remission of melanoma after radiation therapy for patient comfort (BERGMAN, 2007; LARUE \& GILLETTE, 2007).

Ciência Rural, v.48, n.4, 2018. 


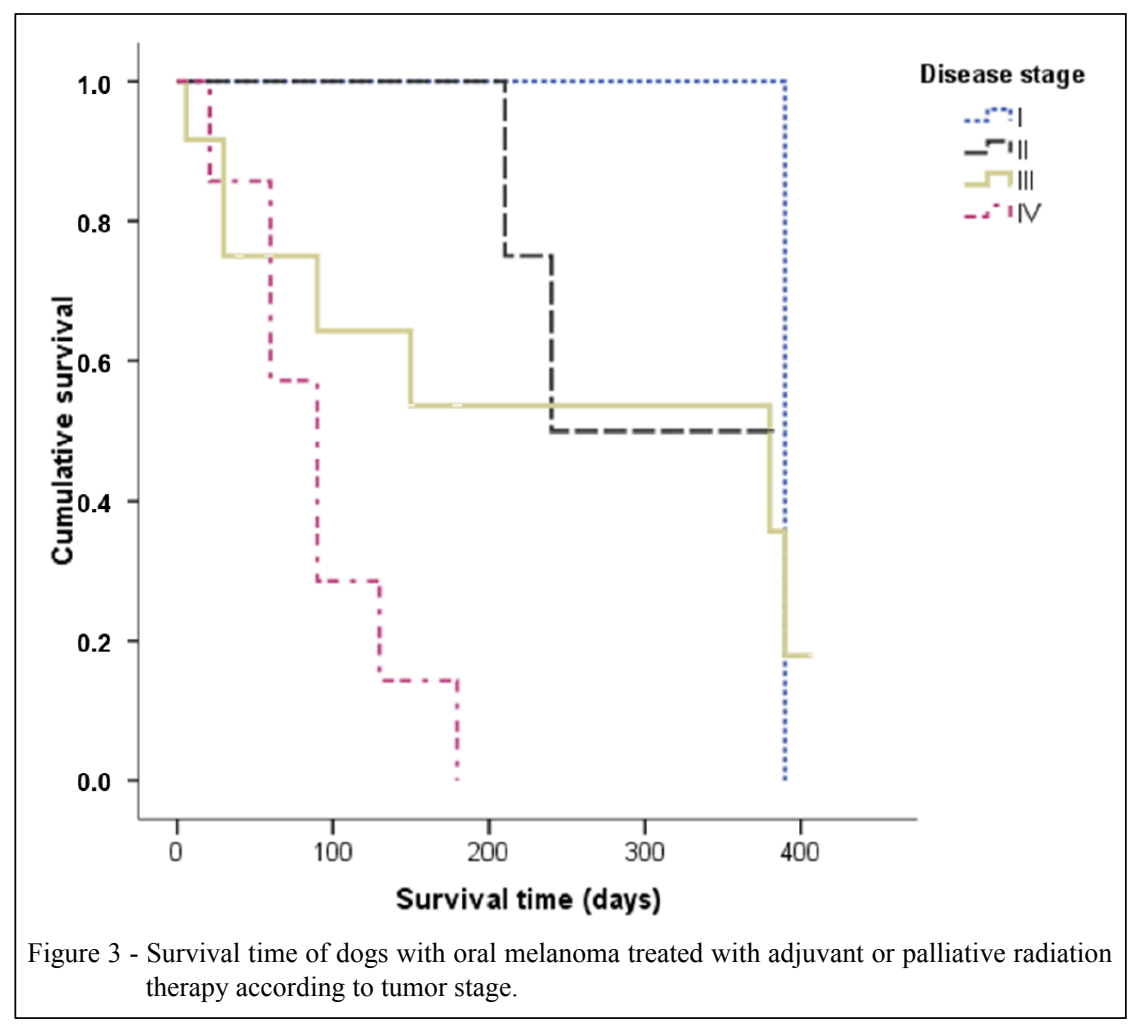

Dogs receiving surgery/chemotherapy/ radiation therapy had a longer ST (mean: 253 days, median: 380 days), followed by animals treated with chemotherapy/radiation therapy (mean: 155 days, median: 150 days), and finally by those treated with radiation therapy alone (mean: 47 days, median: 60

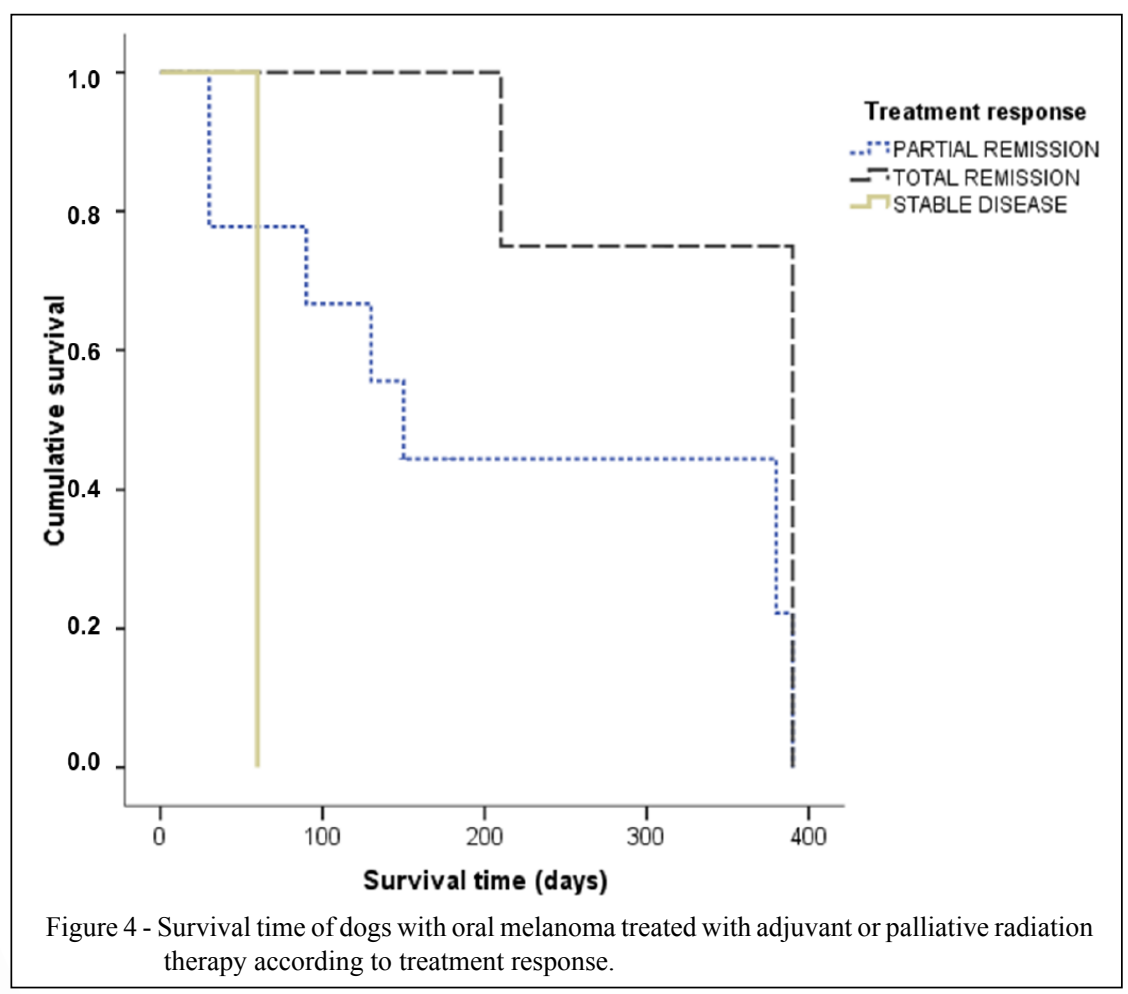

Ciência Rural, v.48, n.4, 2018. 


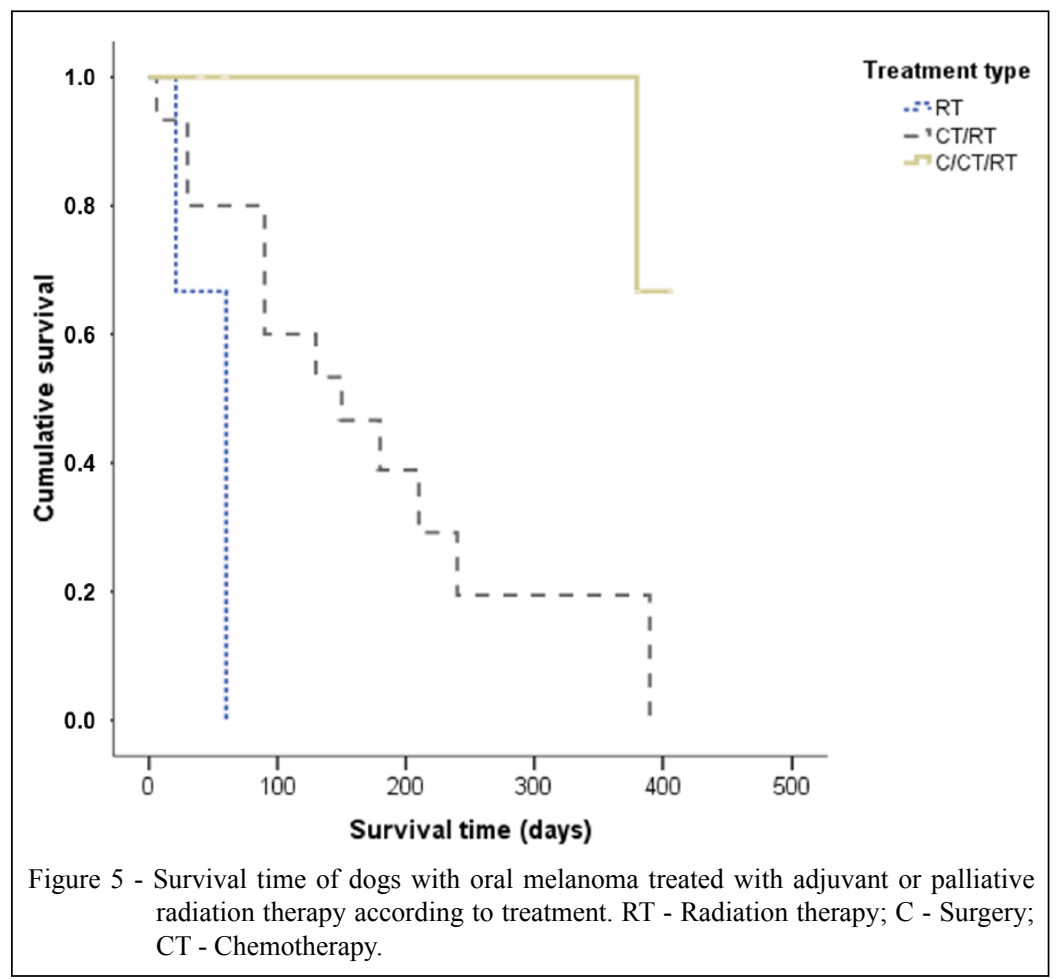

days). Cytoreductive surgery probably increased the ST in these dogs because very bulky masses are difficult to irradiate with orthovoltage radiotherapy, whose dose distribution is more superficial in tissues. Systemic chemotherapy also appears to have been an important factor in increasing patient survival. In this study, it was

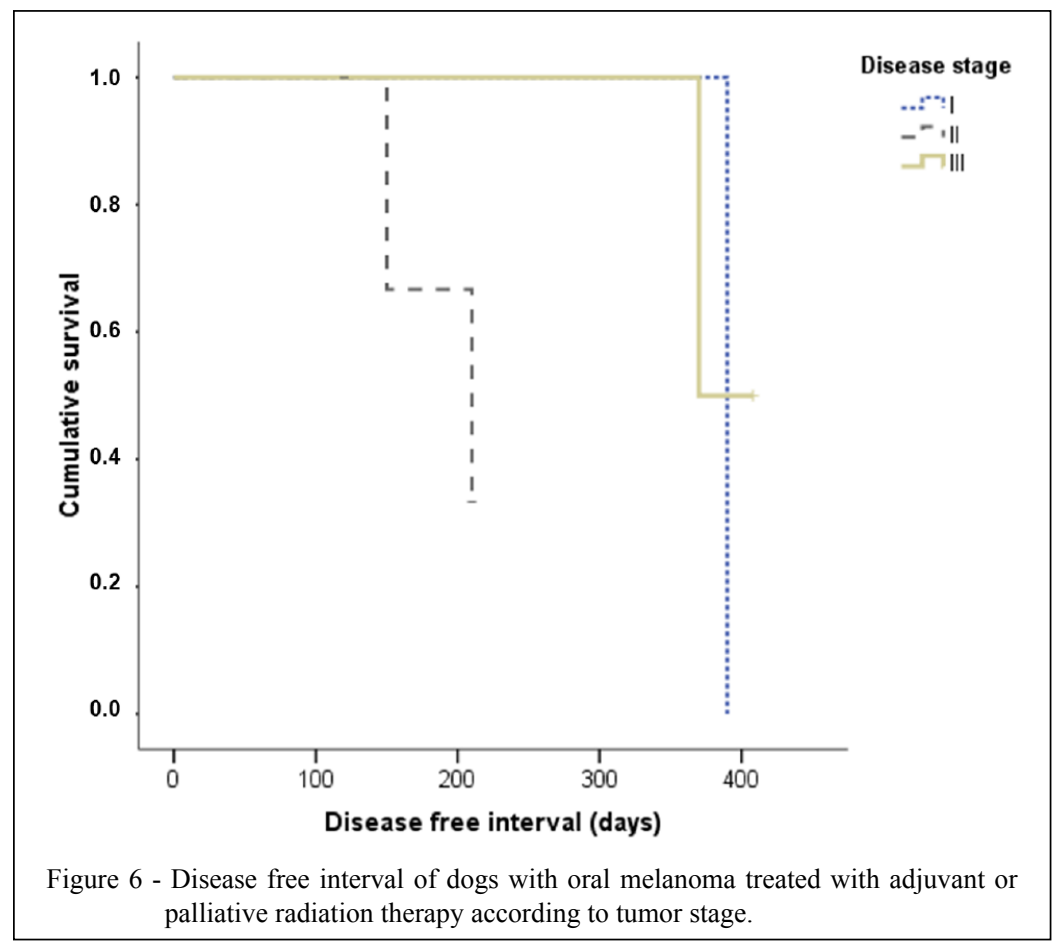

Ciência Rural, v.48, n.4, 2018. 
used for two purposes: to act as a radio-potentiating agent, and to prevent or delay the development of metastases. Previous studies have shown that chemotherapy as a single treatment is ineffective for oral melanomas, so its use in the local control and prevention of metastasis is debatable (RASSNICK et al., 2001). Carboplatin is a second-generation platinum-derived neoplastic agent, originating from cisplatin, and acts by interfering with DNA synthesis (CHUN et al, 2007). Platinum derivatives have been used as radio-potentiating agents, mainly carboplatin. The main mechanisms of interaction between carboplatin and radiation therapy are the increase in the production of single and double strand breaks of DNA caused by radiation and the reduction of intracellular DNA repair mechanisms (YANG et al, 1995). In addition, radiation can enhance the binding of carboplatin to the double strands of DNA under conditions of hypoxia (YANG et al, 1995). The combination of chemotherapy and radiation therapy has improved the response rates and ST of cancer patients. This may indicate that carboplatin in this study may have acted as a radio-potentiating agent or delayed metastasis, and as such played an important role in the treatment of oral melanoma in these dogs.

Reactions of the irradiated normal tissue develop when the rate of cell death is higher than the rate of cell repopulation. Oral mucosa may develop acute reactions, including stomatitis and glossitis. Cutaneous clinical manifestations progress from erythema to desquamation (dry or moist) and epilation. Maximum tissue damage occurs 7-14 days after treatment, and treatment is usually symptomatic (COLLEEN \& MAYER, 2006; LADUE \& KLEIN, 2001). In the present study, the radiation treatment performed was well-tolerated by all dogs, leading only to epilation and mild erythema in the irradiated field. The absence of acute reactions to the radiation observed in our study was due to the hypofractionated protocol used (high doses applied in weekly sessions), which allowed the regeneration of the healthy tissue present in the irradiated field. More severe side effects, including stomatitis and radiodermatitis, would probably be observed in fractionated protocols used in curative-intent radiation therapy.

\section{CONCLUSION}

Radiation therapy is an important cancer treatment modality in humans whose popularity in veterinary medicine in Brazil has been gradually growing. Adjuvant radiation (after incomplete surgeries) or palliative therapy (in unresectable masses) may contribute to partial tumor remission and better patient quality of life, especially at stages III and IV, leading to mild and self-limiting side effects. In this study, systemic chemotherapy was associated with better response rates and ST when used in combination with radiation therapy. Radiation therapy should be considered as an adjuvant or palliative therapy for the treatment of oral canine melanoma.

\section{ACKNOWLEDGEMENTS}

To Fundação de Amparo à Pesquisa do Estado do Rio de Janeiro (FAPERJ)

\section{SOURCES OF ACQUISITION}

${ }^{\text {aPropofol }}{ }^{\circledR} 10 \mathrm{mg}$, Biosintética, São Paulo./SP.

${ }^{b}$ Forane ${ }^{\circledR}$, Abbott, Rio de Janeiro/RJ.

'B-platin 450mg, Blausigiel, São Paulo/SP.

${ }^{\mathrm{d} B o n a r}$ 15UI, Biosintética, São Paulo/SP.

\section{DECLARATION OF CONFLICT OF INTEREST}

The authors declared no potential conflicts of interest with respect to the research, authorship, and/or publication of this article.

\section{REFERENCES}

BATEMAN, K.E. et al. 0-7-21 radiation therapy for the treatment of canine oral melanoma. Journal of Veterinary Internal Medicine, v. 8, n. 4, p. 267-272, 1994. Available from: <https:// doi.org/10.1111/j.1939-1676.1994.tb03231.x>. Accessed: mar. 19, 2018. doi: 10.1111/j.1939-1676.1994.tb03231.x.

BERGMAN, P.J. Canine Oral Melanoma. Clinical Techniques in Small Animal Practice, v. 22, n. 2, p. 55-60, 2007. Available from: $<$ https://doi.org/10.1053/j.ctsap.2007.03.004>. Accessed: mar.19, 2018. doi: 10.1053/j.ctsap.2007.03.004.

BLACKWOOD, L.; DOBSON, J.M. Journal of American Veterinary Medical Association, v. 209, n. 1, p. 98-102, 1996. Available from: <https://www.ncbi.nlm.nih.gov/pubmed/8926220>. Accessed: mar.19, 2018

COLLEEN, E.B.; MAYER, M.N. Acute Effects of Radiation Treatment: Skin Reactions. Canadian Veterinary Journal, v. 47, n. 9, p. 931-935, 2006. Available from: $<$ https://www.ncbi.nlm.nih. gov/pmc/articles/PMC1555679>. Accessed: mar.19, 2018.

CHUN, R. et al. Cancer chemotherapy. In: WITHROW S.J. \& MACEWEN E.G. (Eds). Small Animal Clinical Oncology. Philadelphia: W.B. Saunders, 2007. p. 167-192.

FREEMAN, K.P. et al. Treatment of dogs with oral melanoma by hypofractionated radiation therapy and platinum-based chemotherapy (1987-1997). Journal of Veterinary Internal Medicine, v. 17, n. 1, p. 96-101, 2003. Available from: <https:// doi.org/10.1111/j.1939-1676.2003.tb01329.x>. Accessed: mar.19, 2018. doi: 10.1111/j.1939-1676.2003.tb01329.x.

HAHN, K.A. et al. Canine oral malignant melanoma: prognostic utility of an alternative staging system. Journal of Small Animal Practice, v. 35, n. 5, p. 251-256, 1994. Available from: <https:// doi.org/10.1111/j.1748-5827.1994.tb03273.x>. Accessed: mar.19, 2018. doi: 10.1111/j.1748-5827.1994.tb03273.x. 
HARVEY, H.J. et al. Prognostic criteria for dogs with oral melanoma. Journal of American Veterinary Medical Association, v. 178, n. 6 , p. 580-582, 1981. Available from: <https://www.ncbi.nlm.nih.gov/ pubmed/7263464>. Accessed: mar.19, 2018.

LADUE, T;; KLEIN. M.K. Toxicity Criteria of the Veterinary Radiation Therapy Oncology Group. Veterinary Radiology and Ultrasound, v. 42, n. 5, p. 475-476, 2001. Available from: $<$ https://doi.org/10.1111/j.1740-8261.2001. tb00973.x>.Accessed: mar.19, 2018. doi: 10.1111/j.1740-8261.2001.tb00973.x.

LARUE, S.M.; GILLETTE, E.L. Radiation Therapy. In: WITHROW, S.J. \& MACEWEN, E.G. (Eds). Small Animal Clinical Oncology. Philadelphia: W.B. Saunders, 2007. p. 193-210.

MACEWEN, E.G. et al. Canine oral melanoma: comparison of surgery versus surgery plus Corynebacterium parvum. Cancer Investigation, v. 4, n. 5, p. 397-402, 1986. Available from: < https:// www.ncbi.nlm.nih.gov/pubmed/3801954>. Accessed: mar.19, 2018.

OGILVIE, G.K.; MOORE, A.S. Tumors of the oral cavity. In: OGILVIE, G.K. \& MOORE, A.S. (Ed). Managing the Veterinary Cancer Patient: a Practice Manual. Trenton: Veterinary Learning Systems, 1995. p. 332-336.
PROULX, D.R. et al. A retrospective analysis of 140 dogs with oral melanoma treated with external beam radiation. Veterinary Radiology and Ultrasound, $v .44$, n. 3, p. 352-359, 2003. Available from: $<\mathrm{https} / /$ doi.org/10.1111/j.1740-8261.2003.tb00468.x>. Accessed: mar. 19, 2018. doi: 10.1111/j.1740-8261.2003.tb00468.x.

RASSNICK, K.M. et al. Use of carboplatin for treatment of dogs with malignant melanoma: 27 cases (1989-2000). Journal of American Veterinary Medical Association, v. 218, n. 9, p. 1444-1448, 2001. Available from: <https://www.ncbi.nlm.nih.gov/ pubmed/11345308>. Accessed: mar.19, 2018.

SPANGLER, W.L.; KASS. P.H. The histologic and epidemiologic bases for prognostic considerations in canine melanocytic neoplasia. Veterinary Pathology, v. 43, n. 2, p. 136-149, 2006. Available from: $<$ https://www. ncbi.nlm.nih.gov/pubmed/16537931>. Accessed: mar.19, 2018.

YANG, L.X. et al. Production of DNA double-strand breaks by interactions between carboplatin and radiation: a potential mechanism for radiopotentiation. Radiation Research, v. 143, n. 3, p. 309-315, 1995. Available from: <https://www.ncbi.nlm.nih. gov/pubmed/7652169>. Accessed: mar.19, 2018. 